\title{
Ultrasound guided injection of recalcitrant plantar fasciitis
}

\author{
David Kane, Thomas Greaney, Barry Bresnihan, Robert Gibney, Oliver FitzGerald
}

\begin{abstract}
Objective-To determine the effect of ultrasound guided injection in recalcitrant idiopathic plantar fasciitis.

Methods-Four patients with a clinical diagnosis of idiopathic plantar fasciitis, who were unresponsive to palpation guided injection with triamcinolone acetonide and local anaesthetic, underwent ultrasonographic examination of the heel. Results-The following ultrasonographic features were noted:- (a) increased thickness of plantar fascia in symptomatic heels compared with asymptomatic heels, (b) loss of distinction of the distal plantar fascia borders, (c) reduced echogenicity of the plantar fascia. Ultrasound guided injection of the enlarged, hypoechoic plantar fascia resulted in complete relief in four of five heels(mean duration of follow up=24 months) in three cases. One patient developed a recurrence of symptoms after six months.

Conclusion-Ultrasound allows for confirmation of the clinical diagnosis and ultrasound guided injection produces a good clinical response when unguided injection is unsuccessful. The technique is quick, inexpensive, and entails no radiation exposure.
\end{abstract}

(Ann Rheum Dis 1998;57:383-384)

Plantar fasciitis is characterised by heel tenderness of gradual onset, localised to the medial process of the calcaneal tuberosity and exacerbated by weight bearing. ${ }^{1}$ Diagnosis is usually made on clinical grounds. Ultrasonography of the heel is useful in confirming the diagnosis, especially when alternative pathology such as fascia rupture is suspected. ${ }^{23}$

Injection of corticosteroid at the point of maximal tenderness on palpation is an effective treatment but some patients require multiple injections. The response rate to repeated injection is not known and it may predispose to fascial rupture or fat pad atrophy. ${ }^{4}$ In recalcitrant cases the use of bone scintigraphy to guide injection of the plantar fascia resulted in complete relief in 12 of $15(80 \%)$ patients in one study. ${ }^{5}$ Ultrasound guided injection of other joints and associated structures has already been described. ${ }^{6}$ Ultrasound allows direct visualisation of the affected structures and consequently is more accurate. Unlike bone scintigraphy it is quick, inexpensive, and entails no radiation exposure. We examined the use of ultrasound guided injection in four patients with recalcitrant plantar fasciitis.

\section{Methods}

Four patients with a clinical diagnosis of idiopathic plantar fasciitis-unresponsive to one or more unguided injections of $10 \mathrm{mg}$ triamcinolone acetonide and $1 \mathrm{ml}$ xylocaine $2 \%$ - underwent ultrasound examination of the heel. Real time ultrasound was performed with a 7.5 MHz linear array transducer (Acuson) on both symptomatic and asymptomatic heels. The maximum thickness of the plantar fascia was measured on a longitudinal view of the heel. Plantar fasciitis was defined as a marked increase in the thickness of the plantar fascia in association with reduced echogenicity or loss of definition of the borders of the fascia distal to the calcaneal insertion, or both (fig 1). ${ }^{23}$
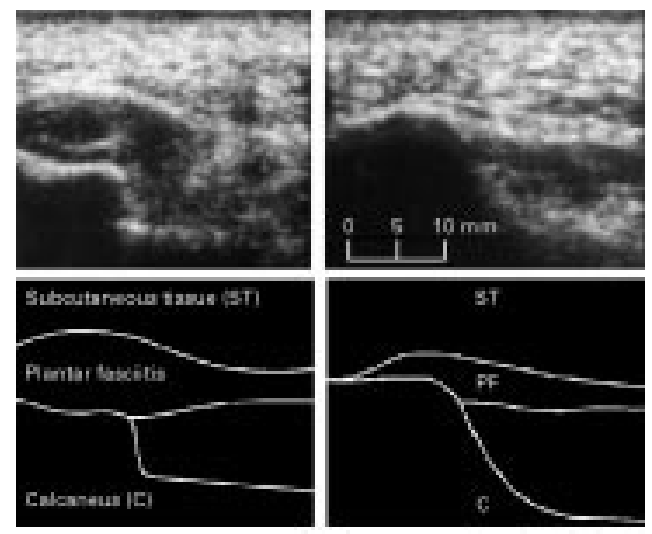

(A) Planiar tascitis

(8) Nomel piantar tascis (PF)

Figure 1 A 7.5 Mhz linear array ultrasound transducer is positioned longitudinally in the midline of the left heel and demonstrates normal plantar fascia with regular fibrillar echotexture. On the right heel, the transducer has been positioned longitudinally over the region of maximal thickness of the plantar fascia, which is grossly thickened with reduced echogenicity. There is loss of definition of fibrillar echotexture and of the fascial borders distal to the anterior border of the calcaneus.

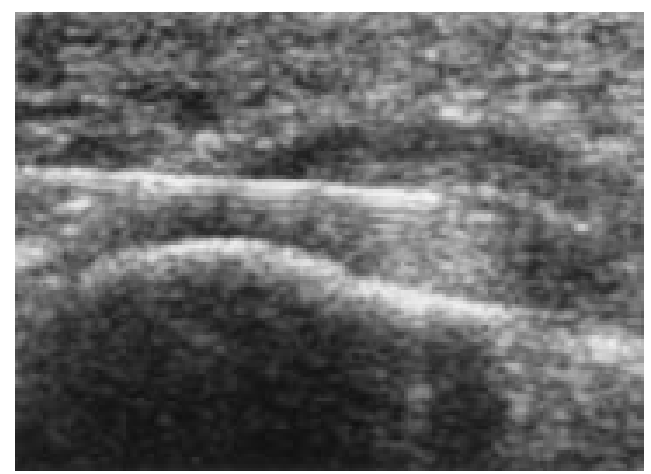

Figure 2 Under ultrasound guidance a 21 gauge needle has been introduced into the thickened plantar fascia via a posterior approach. An injection of triamcinolone acetonide and xylocaine $2 \%$ is distributed evenly into this area and $i$ seen as a hyperechoic solution dispersing around the needle tip.
Accepted for publication 8 May 1998 
Table 1 Ultrasound findings, plain radiography findings, and outcome of ultrasound guided after failure of palpation guided injection in four patients with plantar fasciitis

\begin{tabular}{|c|c|c|c|c|c|c|c|c|c|}
\hline Patient & $\mathrm{Heel}$ & Heel pain & Calcaneal spur & $\begin{array}{l}\text { Maximal thickness of } \\
\text { plantar fascia }\end{array}$ & Hypoechoic & $\begin{array}{l}\text { Loss of border } \\
\text { definition }\end{array}$ & $\begin{array}{l}\text { Palpation } \\
\text { guided injection }\end{array}$ & $\begin{array}{l}\text { Ultrasound guided } \\
\text { injection }\end{array}$ & $\begin{array}{l}\text { Duration of } \\
\text { relief (months) }\end{array}$ \\
\hline 1 & right & + & + & 5.3 & No & No & 1 & 1 & 13 \\
\hline 1 & left & + & + & 8.0 & Yes & Yes & 1 & 1 & 13 \\
\hline 2 & right & 0 & + & $\mathrm{n} / \mathrm{a}$ & $\mathrm{n} / \mathrm{a}$ & $\mathrm{n} / \mathrm{a}$ & - & - & - \\
\hline 2 & left & + & + & 6.0 & Yes & Yes & 2 & 1 & 18 \\
\hline 3 & right & 0 & + & 4.1 & No & No & - & _- & - \\
\hline 3 & left & + & + & 5.5 & Yes & Yes & 1 & 1 & $6^{\star}$ \\
\hline 4 & right & + & + & 7.5 & Yes & Yes & 2 & 1 & 46 \\
\hline 4 & left & 0 & 0 & 4.1 & No & No & - & - & - \\
\hline
\end{tabular}

Symptomatic heels were compared with asymptomatic heels. Ultrasound guided injection was performed with $2 \mathrm{ml}$ of a $50 / 50$ mixture of triamcinolone acetonide $(10 \mathrm{mg} / \mathrm{ml})$ and xylocaine $2 \%$. The injection was performed using a medial or posterior approach into the heel directing a 21 gauge needle into the centre of the hypoechoic, oedematous plantar fascia under real time imaging guidance (fig 2). The dispersal of the hyperechoic injection admixture into the substance of the plantar fascia was confirmed on post-injection ultrasound.

\section{Results}

ULTRASOUND FINDINGS

Four patients with a total of five painful heels, unresponsive to at least one palpation guided injection of the heel, underwent ultrasound examination and ultrasound guided injection (table 1). All patients had failed treatment with physiotherapy and non-steroidal antiinflammatory drugs.

The mean maximal thickness of the plantar fascia was $6.16 \mathrm{~mm}$ in symptomatic heels compared with $4.1 \mathrm{~mm}$ in asymptomatic heels. The plantar fascia was thickened in all five symptomatic heels. Four of five heels demonstrated reduced echogenicity with loss of distal border definition. Two asymptomatic heels had normal ultrasound findings. Ultrasound films were not obtained in one asymptomatic heel.

OUTCOME OF ULTRASOUND GUIDED INJECTION Ultrasound guided injection resulted in complete relief of symptoms in four of five heels. The mean duration of relief of symptoms at the last follow up was 24 months (table 1). One patient had a recurrence of plantar fasciitis after six months that did not respond to repeated injection in combination with further physiotherapy and orthotic supports. She was eventually referred for surgery.

\section{Discussion}

Plantar fasciitis is usually diagnosed on the basis of clinical findings and imaging of the heel is not routinely performed to confirm the diagnosis. ${ }^{1}$ When the clinical presentation is atypical or when symptoms persist despite appropriate treatment the diagnosis can be confirmed by either ultrasonography, bone scintigraphy ${ }^{5}$ or magnetic resonance imaging (MRI). ${ }^{7}$ Ultrasound examination of the heel is very sensitive and specific in the diagnosis of plantar fasciitis. ${ }^{3}$ In contrast with bone scintigraphy and MRI, it is inexpensive, quick, widely available, and does not entail radiation exposure. In this series of patients ultrasound confirmed the suspected clinical diagnosis in all five cases of recalcitrant plantar fasciitis.

Non-surgical treatment consists of heel pads, orthotics, physiotherapy, and heel injection. Palpation guided injection of plantar fasciitis with corticosteroid preparations is an effective and common practice. It is not always successful, however, and multiple injections are occasionally required. This may be because of inaccuracy of injection, obesity, ${ }^{8}$ and underlying biomechanical abnormality of the foot should also be considered. ${ }^{9}$

Ultrasound guidance is now a common technique for fluid aspiration, tissue biopsy or therapeutic injection. We describe a technique of ultrasound guided injection of the heel in four patients with recalcitrant plantar fasciitis that allowed accurate delivery of corticosteroid directly to the thickened oedematous plantar fascia. In four of five heels with plantar fasciitis, ultrasound guided injection of the heel produced a complete clinical response when palpation guided injection had failed. Scintigraphic localisation of injection has been reported to produce a similar rate of clinical response in recalcitrant plantar fasciitis. ${ }^{5}$ As the patients were not randomised in either study this may have occurred with repeated injection whether injection was radiologically guided or not. A prospective randomised trial comparing palpation guided to ultrasound guided injection is required. We conclude that ultrasound guided injection of plantar fasciitis should be considered as an alternative to scintigraphic guided injection when palpation guided injection fails.

We would like to thank Mr Michael Nalty for the design and production of the figures.

1 Schepsis AA, Leach RE, Gorzyca J. Plantar fasciitis. Etiology, treatment, surgical results, and review of the literature. Clin Orthop 1991;266:185-96.

2 Cardinal E, Chem RK, Beauregard CG, Aubin B, Pelletier M. Plantar fasciitis: sonographic evaluation. Radiology 1996;201:257-9.

3 Wall JR, Harkness MA, Crawford A. Ultrasound diagnosis of plantar fasciitis. Foot Ankle 1993;14:465-70.

4 Sellman JR. Plantar fascia rupture associated with corticosteroid injection. Foot Ankle 1994;15:376-81.

5 Dasgupta B, Bowles J. Scintigraphic localisation of steroid Dasgupta B, Bowles J. Scintigraphic localisation of steroid
injection site in plantar fasciitis. Lancet 1995;346:1400-1. injection site in plantar fasciitis. Lancet 1995;346:1400-1. Trophy DP, Cunnane G, FitzGerald O, Gibney RG.
Technical report: ultrasound guidance for injection of soft Technical report: ultrasound guidance for injection of soft
tissue lesions around the heel in chronic inflammatory

7 Kier R. Magnetic resonance imaging of plantar fasciitis and other causes of heel pain. Magn Reson Imaging Clin N Am 1994;2:97-107.

8 Hill JJ Jr, Cutting PJ. Heel pain and body weight. Foot Ankle 1989;9:254-6.

9 Perry J. Anatomy and biomechanics of the hindfoot. Clin Orthop 1983;177:9-15. 